\title{
CORRESPONDENCE
}

These letters respond to the Commentary 'Dangerous assumptions' by R. Pielke Jr, T. Wigley and C. Green (Nature 452, 531-532; 2008) on the scenarios of the Intergovernmental Panel on Climate Change (IPCC).

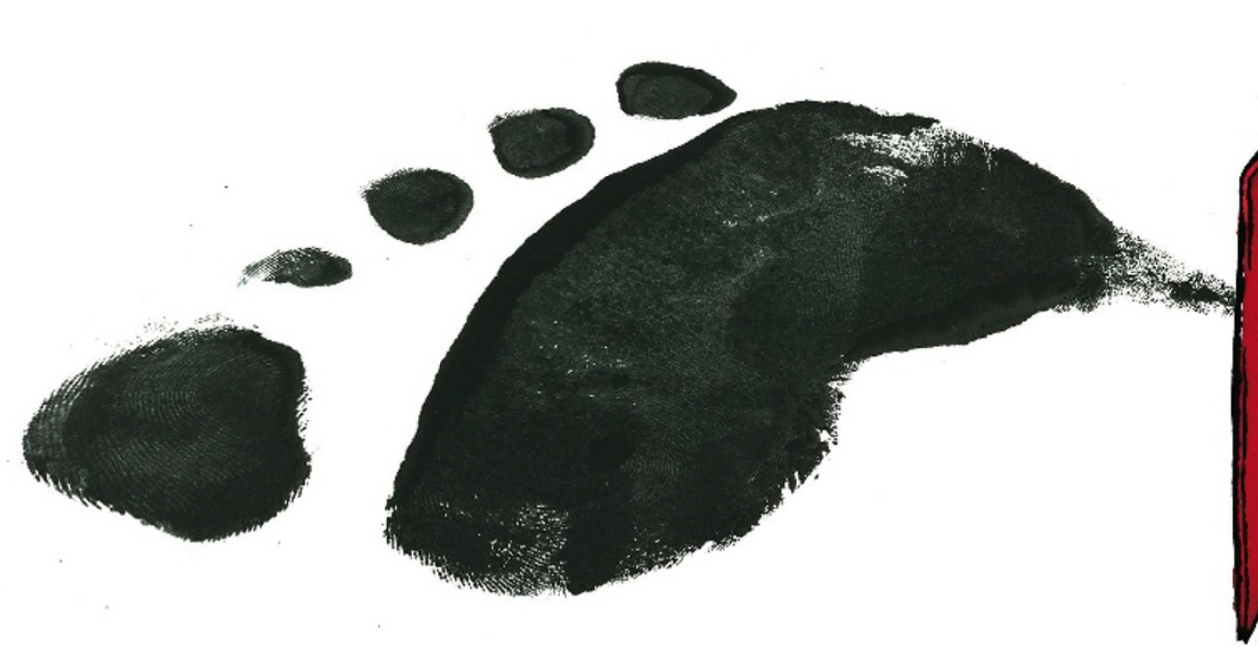

\section{Long-range energy forecasts are no more than fairy tales}

SIR - I largely agree with the overall conclusion of Pielke et al. that the IPCC assessment is overly optimistic, but I fear that the situation is even worse than the authors imply.

Debate about the energy challenge of climate change has ignored several key facts about global energy and its future.

All long-range energy forecasts fail in various ways. The scenarios for 2100 in the 2000 IPCC Special Report on Emissions Scenarios are risible: even if one of them were to approximate actual demand, we will remain ignorant of what its regional and sectoral composition would be a century from now - and it is this that will determine emissions of greenhouse gases. Basing policies on computerized fairy tales is inadvisable.

Why argue about plausible rates of future energy-efficiency improvements? We have known for nearly 150 years that, in the long run, efficiency gains translate into higher energy use and hence (unless there is a massive shift to non-carbon energies) into higher $\mathrm{CO}_{2}$ emissions.
The speed of transition from a predominantly fossil-fuelled world to conversions of renewable flows is being grossly overestimated: all energy transitions are multigenerational affairs with their complex infrastructural and learning needs. Their progress cannot substantially be accelerated either by wishful thinking or by government ministers' fiats.

Carbon sequestration is irresponsibly portrayed as an imminently useful large-scale option for solving the challenge. But to sequester just $25 \%$ of $\mathrm{CO}_{2}$ emitted in 2005 by large stationary sources of the gas $\left(9.6 \mathrm{Gm}^{3}\right.$ at the supercritical density of $0.468 \mathrm{~g} \mathrm{~cm}^{-3}$ ), we would have to create a system whose annual throughput (by volume) would be slightly more than twice that of the world's crude-oil industry, an undertaking that would take many decades to accomplish.

China, the world's largest emitter of $\mathrm{CO}_{2}$, has no intention of reducing its energy use: from 2000 to 2006 its coal consumption rose by nearly 1.1 billion tonnes and its oil consumption increased by $55 \%$.

Consequently, the rise of atmospheric $\mathrm{CO}_{2}$ above
450 parts per million can be prevented only by an unprecedented (in both severity and duration) depression of the global economy, or by voluntarily adopted and strictly observed limits on absolute energy use. The first is highly probable; the second would be a sapient action, but apparently not for this species. Vaclav Smil University of Manitoba, Winnipeg, Manitoba R3T 2N2, Canada

\section{Energy assumptions were reasonable at the time, but not now}

SIR - Pielke et al. correctly point out that almost all of the IPCC emissions scenarios assume continuing improvements in the energy intensity of the global economy and in the carbon intensity of the global energy system, even in the absence of explicit climate policy. This assumption is not hidden, as Pielke et al. imply, and it is not unreasonable.

Over several decades before 2000, that is exactly what happened. Improved manufacturing and buildings, increased efficiency in power production, and increasing 